\title{
MICROSTRUCTURAL INVESTIGATIONS OF ELECTRON BEAM WELDED ALLOY 718
}

\author{
M. Sundararaman and P.J. Potdar \\ Materials Science Division \\ Bhabha Atomic research Centre \\ Mumbai 400 085, India
}

Key words: Alloy 718, electron beam welding, structure integrity, residual stresses

\begin{abstract}
Electron beam welding is used to join components where welding distortions have to be minimized and good weld integrity is a must. This paper reports the results of microstructural investigations carried out on Alloy 718 welded in the aged condition. A region of width $200 \mu \mathrm{m}$ at a distance of $500 \mu \mathrm{m}$ from the fusion zone interface in the heat affected zone (HAZ) showed extensive deformation bands. Micro-hardness measurements showed softening in the HAZ region close to the fusion zone interface and hardness values the same as that of region far away from the weld zone in the rest of the areas including the deformed region. The influence of post weld heat treatments on integrity of weld was carried out. Profuse faulting and twinning and planar arrangement of dislocations were observed in the deformed region and in the areas close to fusion interface in the HAZ, dissolution of $\gamma^{\prime \prime}$ particles has occurred. The present observations are rationalized in terms of the temperature seen in the HAZ zone and also the residual strain generated due to heating and microstructural changes during welding.
\end{abstract}

\section{Introduction}

Alloy 718 is a precipitation strengthened, nickel base superalloy originally developed to provide a combination of high strength at intermediate temperatures and good weldability. It is one of the most frequently used in high performance gas turbine engine. Many components made of this alloy are fabricated by welding and the life of these components is determined by the properties of weld and the HAZ regions. Alloy 718 is considered easy to weld because of the sluggish precipitation kinetics of the main strengthening $\gamma^{\prime \prime}$ phase $[1,2]$. Different techniques, like TIG, electron beam or laser welding have been adopted in practice to fabricate components. The type of welding, the post weld heat treatment and the initial microstructures chosen depend upon the ultimate application of the component. Welding has been carried out either in the solution treated or in the age hardened condition. Precipitation hardened condition is employed when weld distortions are to be minimized. Similarly, electron beam or laser welding is employed to produce narrow HAZ[3]. Although, the weldability is considered good and the alloy is highly resistant to strain age cracking during stress relief, the alloy is susceptible to liquation cracking in the HAZ due to the formation of a liquid film at grain boundaries or at particle matrix interfaces during the weld thermal cycle. $[4,5]$. The liquid film originates from the constitutional liquation at the interface between the primary MC carbides, the Laves phase or the $\delta$ particles and the $\gamma$ matrix. Similarly, the concentration of minor constituents like boron which preferentially segregate to grain boundaries, the grain size etc are reported to be influencing the micro-cracking or micro-fissure susceptibility of this alloy[6]. 
The physical metallurgy of this alloy has been studied in detail [7-11]. The sequence in which the metastable $\gamma^{\prime \prime}$ phase $\left(\mathrm{DO}_{22}\right.$ structure with $\mathrm{Ni}_{3}(\mathrm{Nb}, \mathrm{Al}, \mathrm{Ti})$ composition), the equilibrium intermetallic $\delta$ phase ( $\left(\mathrm{D}_{\mathrm{a}}\right.$ structure with $\mathrm{Ni}_{3} \mathrm{Nb}$ composition) and the carbide phases (MC and $\mathrm{M}_{23} \mathrm{C}_{6}$ ) evolve in these alloys has been well established[R]. The evolution of various morphologies of $\gamma^{\prime \prime}$ precipitates, the kinetics of their growth and coarsening, the heterogeneous and the homogeneous nucleation of equilibrium $\delta$ phase and the stability range of various intermetallic phases have been studied and already reported in the literature $[8,11,12]$.

EB welding is used extensively in many critical areas where weld distortion has to be minimized. The main aim of this work is to assess the microstructural integrity of weld joint of Alloy 718 which was EB welded in the age hardened microstructural condition. This paper describes the results of a detailed investigation carried out using optical and transmission electron microscopy on EB welded Alloy 718. The microstructures generated in the HAZ region are rationalized in terms of the TTT diagram available for this alloy. The influence of post weld heat treatment on the integrity of weld has also been discussed in this paper.

\section{Experimental Procedure}

The nominal chemical composition of the alloy 718 used in this work is given in table 1. Plate of Alloy 718 of dimensions, (thickness $7 \mathrm{~mm}$, length $100 \mathrm{~mm}$ and width $70 \mathrm{~mm}$ ) subjected to standard heat treatment was electron beam welded using bead on plate technique to full penetration. The standard heat treated condition is the one in which the specimen is subjected to solution treatment at $980^{\circ} \mathrm{C}$ for 30 minutes and then given the double ageing treatment by holding it at $720^{\circ} \mathrm{C}$ for 8 hours followed by slow cooling to $620^{\circ} \mathrm{C}$ and then holding there for 8 hours before final air cooling to room temperature. The welded specimen was supplied by GTRE, Bangalore, India. Typical weld cross section is shown in figure 1. Samples for further examination were cut from the welded plate perpendicular to the welding direction. Some pieces of the weld specimens were subjected to post weld heat treatments. The welded specimens directly subjected to standard double ageing treatment are designated as DA. Another set of

Table I Nominal Composition of Alloy 718

\begin{tabular}{|c|c|c|c|c|c|c|c|c|c|c|}
\hline Element & $\mathrm{Ni}$ & $\mathrm{Cr}$ & $\mathrm{Fe}$ & $\mathrm{Mo}$ & $\mathrm{Nb}$ & $\mathrm{Al}$ & $\mathrm{Ti}$ & $\mathrm{Mn}$ & $\mathrm{Si}$ & $\mathrm{C}$ \\
\hline Conc.(wt.\%) & 52.5 & 19.0 & 18.2 & 3.0 & 5.35 & 1.0 & 0.5 & 0.21 & 0.20 & 0.04 \\
\hline
\end{tabular}

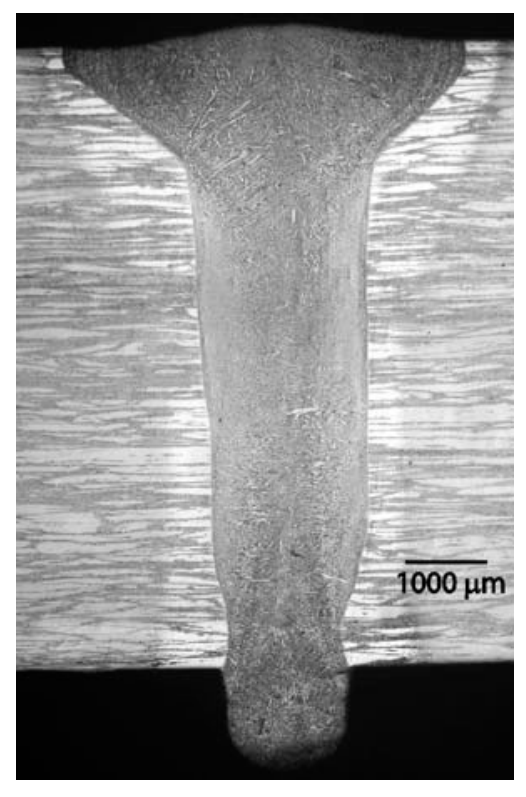

Figure 1. Cross section of electron beam welded Alloy 718. 

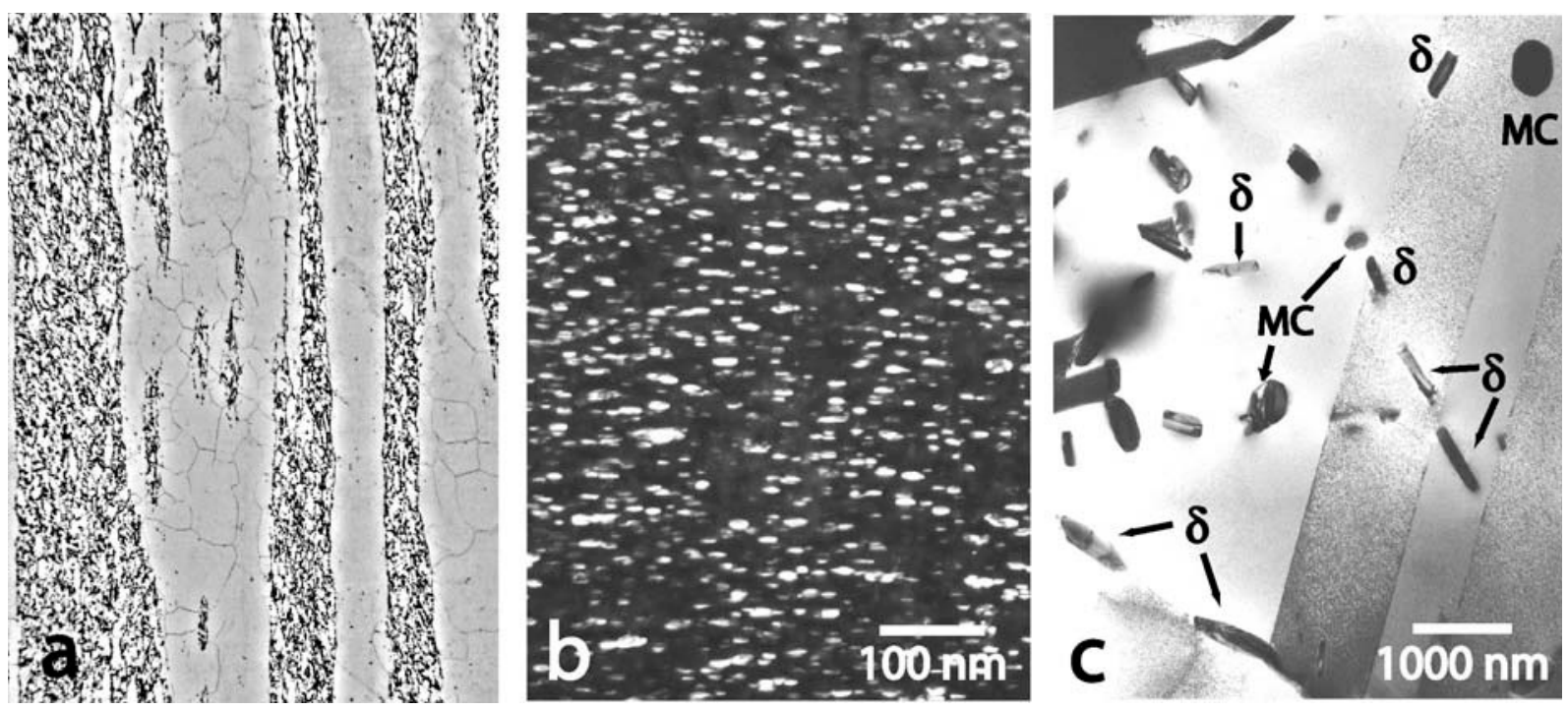

Figure 2. Microstructure of Alloy 718 base material; (a) Bimodal distribution of grains, (b) uniform distribution of $\gamma^{\prime \prime}$ particles and (c) MC carbides and $\delta$ particles in the matrix.

samples were subjected to stress relieving treatment at $980^{\circ} \mathrm{C}$ for 15 minutes before carrying out double ageing treatment and they are designated as STA.

Micro-hardness measurements were taken across the weld from as received, DA and STA specimens using Future-Tech Corp, Japan, micro-hardness tester (Model No: FM-7) with a 50 gm load and a dwell time of 10 seconds. Thin slices of $0.3 \mathrm{~mm}$ thickness were cut parallel to the fusion surface using a Buehler low speed saw at different distances from fusion zone to the matrix through the heat affected (HAZ) region. Specimens for TEM were prepared by elctropolishing $3 \mathrm{~mm}$ discs punched from these thin foils in a solution containing $20 \%$ perchloric acid and $80 \%$ ethanol at $-30^{\circ} \mathrm{C}$ and at $18 \mathrm{~V}$ in dual jet electropolishing unit. The $\gamma^{\prime \prime}$ precipitate size given in table 2 is the average length measurement taken on at least 300 particles imaged in dark field using superlattice reflections corresponding to them.

\section{Results}

\section{$\underline{\text { Base Material Microstructure }}$}

The microstructure of base material shown in figure 2 gives the appearance of banded structure with light and dark regions. Equiaxed grains could be noticed within the light as well as the dark bands with the light areas having a larger grain size compared to dark areas. Such duplex structures have been reported in samples deformed in hot compression at temperatures above $1000^{\circ} \mathrm{C}$ during alloy processing [13]. This microstructure could have been produced during the processing route. The standard heat treatment is not expected to alter this structure since the temperatures involved during the heat treatment are below $1000^{\circ} \mathrm{C}[13]$. TEM examination showed a uniform distribution of $\gamma^{\prime \prime}$ particles in the alloy with an average diameter of $\sim 12 \mathrm{~nm}$ (Fig. 2b). Some primary MC carbide particles and also blocky and needle shaped $\delta$ particles could be seen within the matrix as well as at the grain boundaries.

\section{$\underline{\text { Weld Microstructure }}$}

No macro or micro cracking were observed in the EB welded specimen at the optical level. Fig. 3a is a typical micrograph showing all regions, from fusion zone to the base material through HAZ. No grain growth appears to have occurred in the HAZ region. Extensive deformation bands / twins could be noticed within a small band of region of thickness $\sim 200 \mu \mathrm{m}$, at a distance 


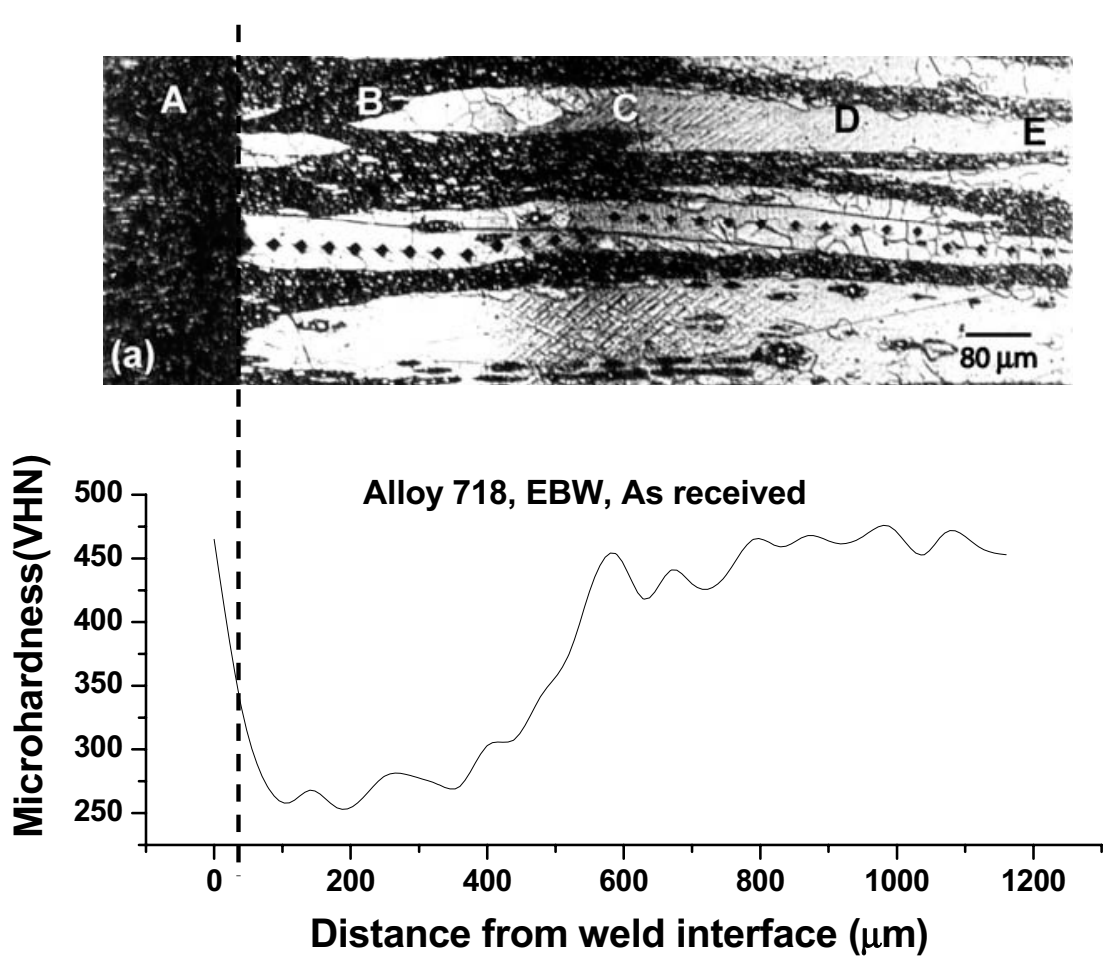

Figure 3. Microhardness profile across the weld structure; (a) optical micrograph and (b) microhardness plot.
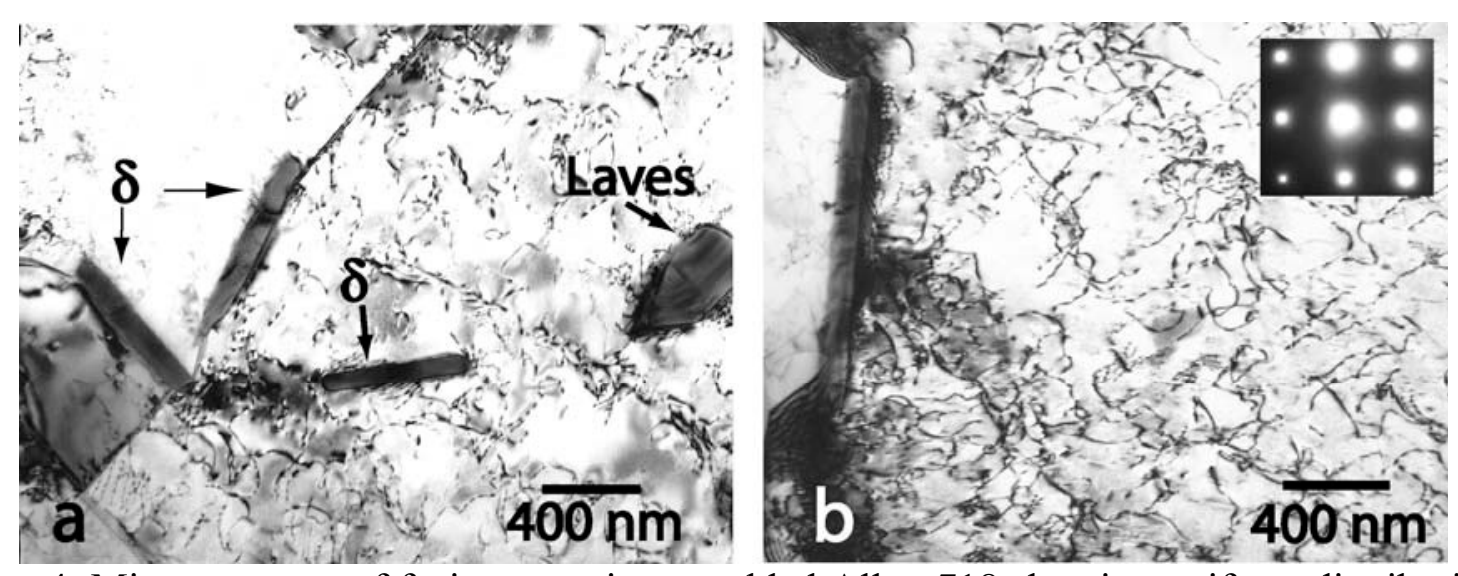

Figure 4. Microstructure of fusion zone in as welded Alloy 718 showing uniform distribution of high density of dislocations. The Laves phase and $\delta$ particles could be seen in (a).

of about $\sim 400 \mu \mathrm{m}$ from the fusion zone-HAZ interface. The detailed microstructure of this region is discussed later. A micro-hardness traverse taken across the weld from the fusion zone to the base matrix is shown in figure $3 \mathrm{~b}$. The indentation spots are shown in the optical micrograph in figure $3 \mathrm{a}$. The micro-hardness in the fusion zone region is high and comparable to that of base material. It started decreasing near the fusion zone-HAZ interface, reaching a constant value of $\sim 250 \mathrm{VHN}$ in the HAZ region up to a distance of $\sim 400 \mu \mathrm{m}$ from the interface. The hardness values gradually started increasing thereafter and reached the base material value at a distance of $\sim 600 \mu \mathrm{m}$ from the fusion zone interface. It is clear from this figure that the region where the hardness has started increasing corresponds to the area $\mathbf{C}$ where extensive deformation bands are noticed.

Detailed TEM examination of specimens revealed different microstructures at various distances from the fusion zone. Random distribution of high density of dislocations could be noticed within the fusion zone ( region marked $\mathbf{A}$ in figure 3a, Fig. 4). Inter - and intra-granularly 

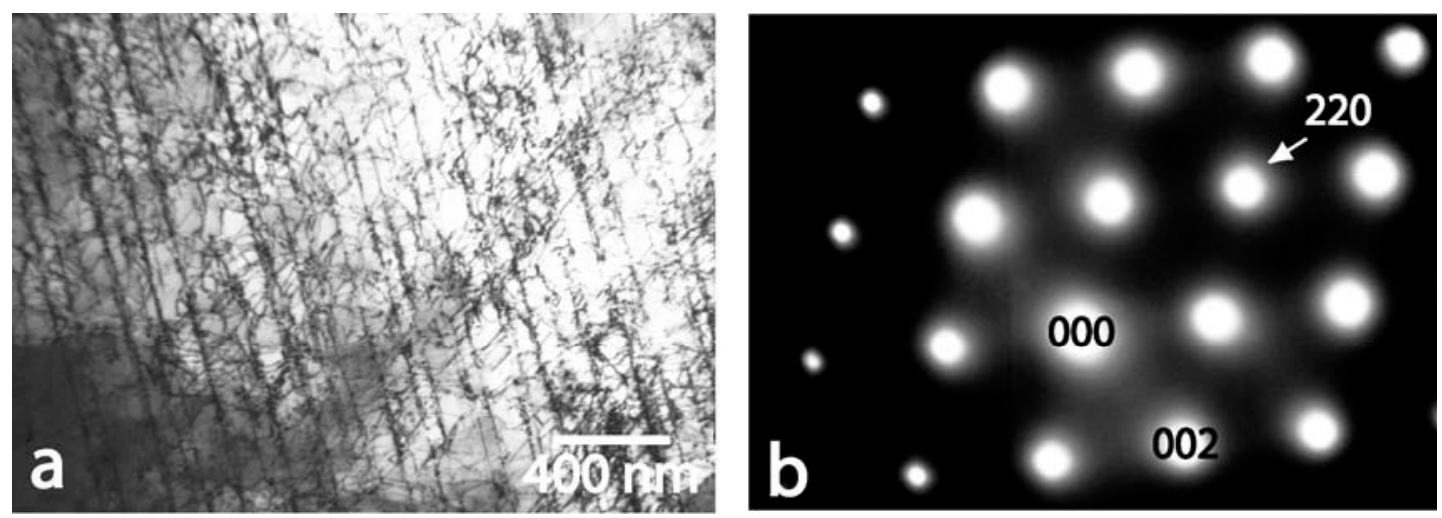

Figure 5. Microstructure of region B in figure 3a; (a) planar arrangement of dislocations and (b) [1-10] zone axis SAD pattern indicating absence of $\gamma^{\prime \prime}$ reflection.
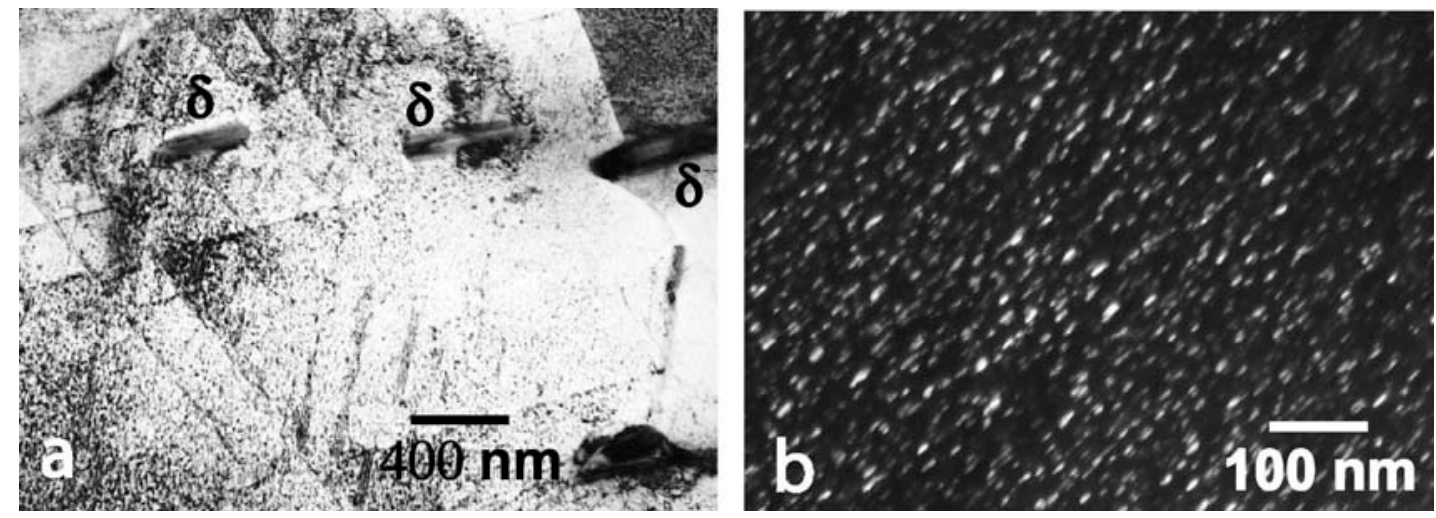

Figure 6. Microstructure of region $\mathrm{C}$ in figure 3a; (a) deformation bands and faulting within the matrix and (b) uniform distribution of $\gamma^{\prime \prime}$ particles.

distributed primary carbides, Laves phase and $\delta$ particles were also seen. No evidence of superlattice reflections corresponding to $\gamma^{\prime \prime}$ particles could be observed in the selected area diffraction (SAD) pattern (inset in figure $4 \mathrm{~b}$ ) indicating that its precipitation has not occurred during solidification. Similar microstructure evolved in the heat affected zone close to the interface (Region $\mathbf{B}$ in figure 3a). However, the dislocations are arranged predominantly in planar arrays here (figure 5a) indicating that the stacking fault energy of the matrix is low [14]. The variation in stacking fault energy between different regions could be attributed to the difference in the matrix composition between fusion zone and HAZ as a result of profuse
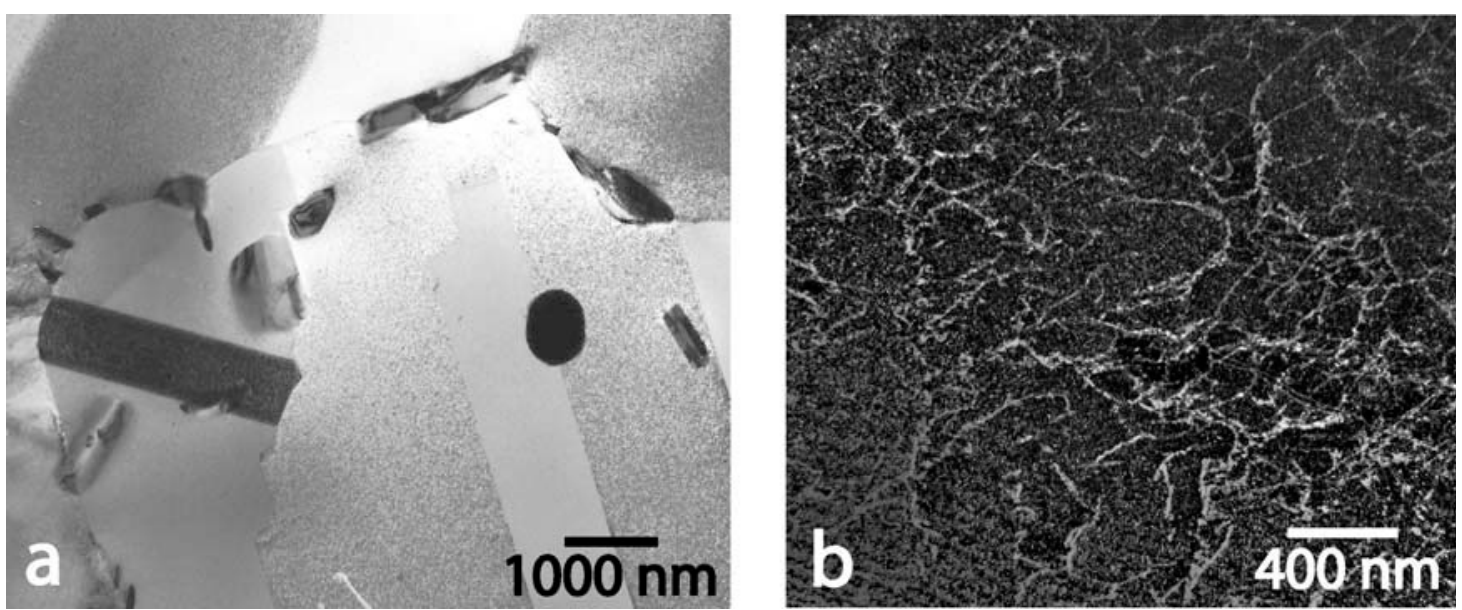

Figure 7. Microstructure of region D in figure 3a; (a) bright field micrograph and (b) distribution of dislocations in the matrix. 
precipitation of primary carbides and Laves phases in the fusion zone during solidification. The absence of superlattice reflection corresponding to $\gamma^{\prime \prime}$ particles indicated that these precipitates have completely dissolved (Fig. 5b). In the region marked $\mathbf{C}$ in figure 3a, uniform distribution of $\gamma^{\prime \prime}$ particles could be observed (Fig.6) and its average size is very close of the base material (table 2 ). The dislocations are often confined to deformation bands lying on $\{111\}$ planes and most of them have split into partials. In the region shown $\mathbf{D}$ in figure $3 \mathrm{a}$, the dislocation density has reduced considerably and its arrangement is random (fig. 7). The $\gamma^{\prime \prime}$ particle size in this case is similar to that of base material (table 2). The distribution of carbides and $\delta$ particles in the HAZ region is very similar to that observed in the base material. The microstructure in region marked $\mathbf{E}$ in figure 3a (far away from the fusion zone interface) is similar to that of base material described in figure 2 .

\section{$\underline{\text { Post Weld Heat Treated Microstructure }}$}

The post weld heat treatments (DA and STA) did not result in the generation of cracks either in the fusion zone or heat affected zone in the material. In fact, the narrow band of deformed region seen in the HAZ in the as welded sample has disappeared after post weld heat treatment (Fig. 8 and Fig. 9). Micro-hardness profile remained nearly flat across the HAZ region in both DA and STA specimens though the hardness values were slightly lower for STA specimens compared to DA specimens. TEM examination of fusion zone in DA and STA samples revealed uniform

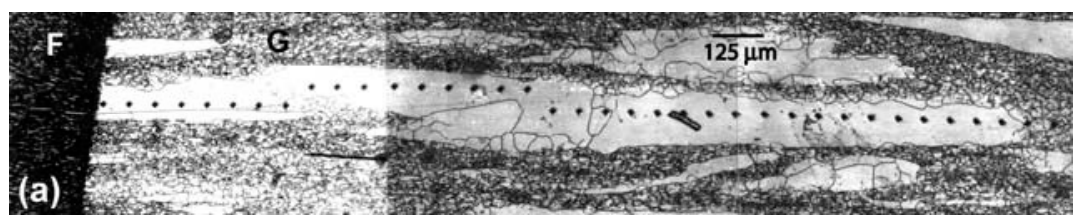

Figure 8. Optical micrograph of cross section of DA specimen.
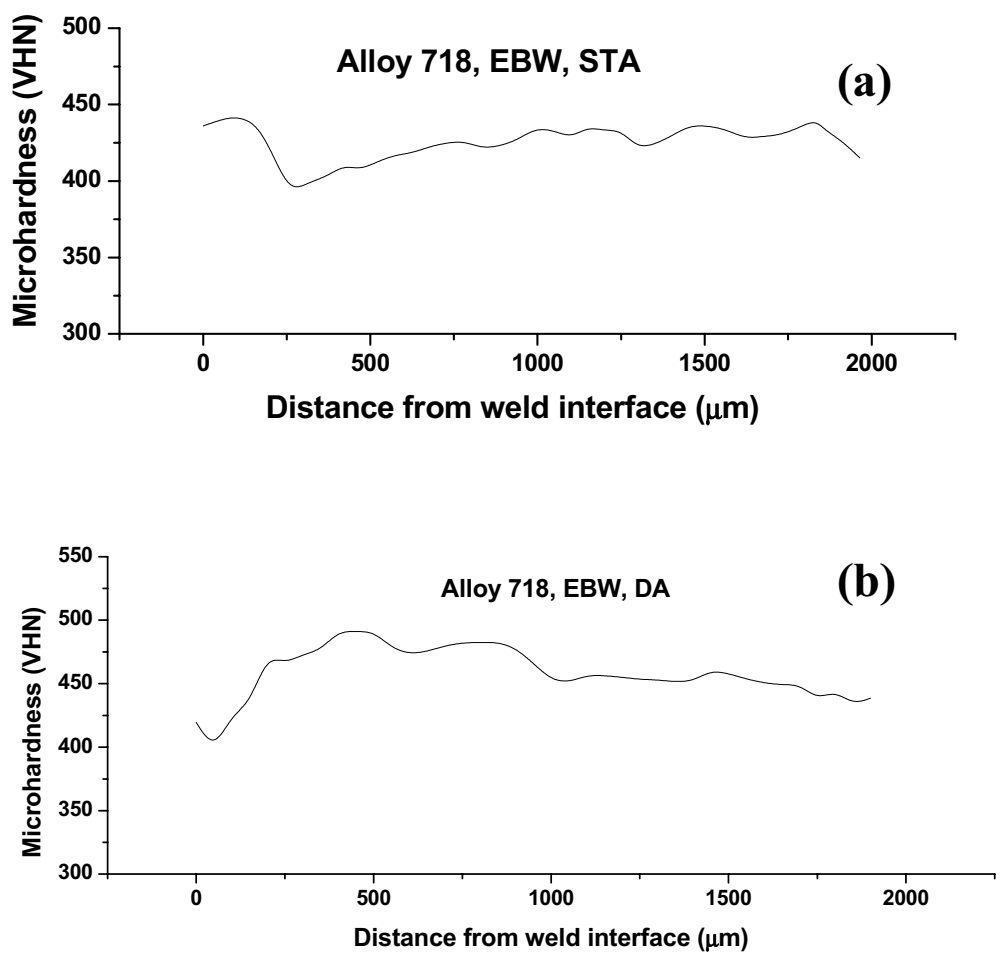

Figure 9. Microhardness profile of (a) DA and (b) STA specimen. 
distribution of high density of dislocations in the matrix (Figures 10a and 10b). However, in the HAZ and the base material, the dislocations appeared to have almost completely annealed out (Fig. 11a and 11b). Precipitation of uniform distribution of $\gamma^{\prime \prime}$ particles has occurred in all regions of the specimen, from fusion zone to the base material. From the table 2, it is clear that there is no variation in $\gamma^{\prime \prime}$ particle size $(11.6 \mathrm{~nm})$ in the entire sample in the STA specimen while in the case of DA specimen, $\gamma^{\prime \prime}$ particle size in the fusion zone is comparable to that of STA specimen but its value has increased in the base material. This could be attributed to two standard ageing treatments seen by the base material of DA specimen without any intermediate solution treatment. This variation in size has not brought about any significant change in the hardness value.

\section{Discussion}

The present investigation did not reveal any micro-fissures or micro-cracks in the fusion zone or HAZ of EB welded samples and the integrity of the weld was found to be good in as welded and also in post weld heat treated specimens. Different reasons have been cited in the literature for non-observation of micro-fissures in the HAZ in welded Alloy 718. These include the alloy composition [15], the microstructure [5], the precipitation of different phases [4] and distribution of minor elements [6]. It has been reported by Vincent [5] that finer grains resulted in the reduction or elimination of liquation fissures in HAZ in Alloy 718. It is possible that the duplex microstructure consisting of nearly equal volume fraction of very fine and large grains has resulted in the suppression of micro-fissures in the present case. The absence of extensive precipitation of carbides and $\delta$ particles at the grain boundaries and the relatively fast cooling provided by the heat sinks might have reduced the time available for liquation to occur at particle-matrix boundaries. It has been reported that micro-crack / micro-fissure susceptibility increases with increasing the boron content of the alloy [6]. Though the concentration of boron has not been determined in the present study, the non observation of micro-cracks / microfissures suggest that its value might be low.
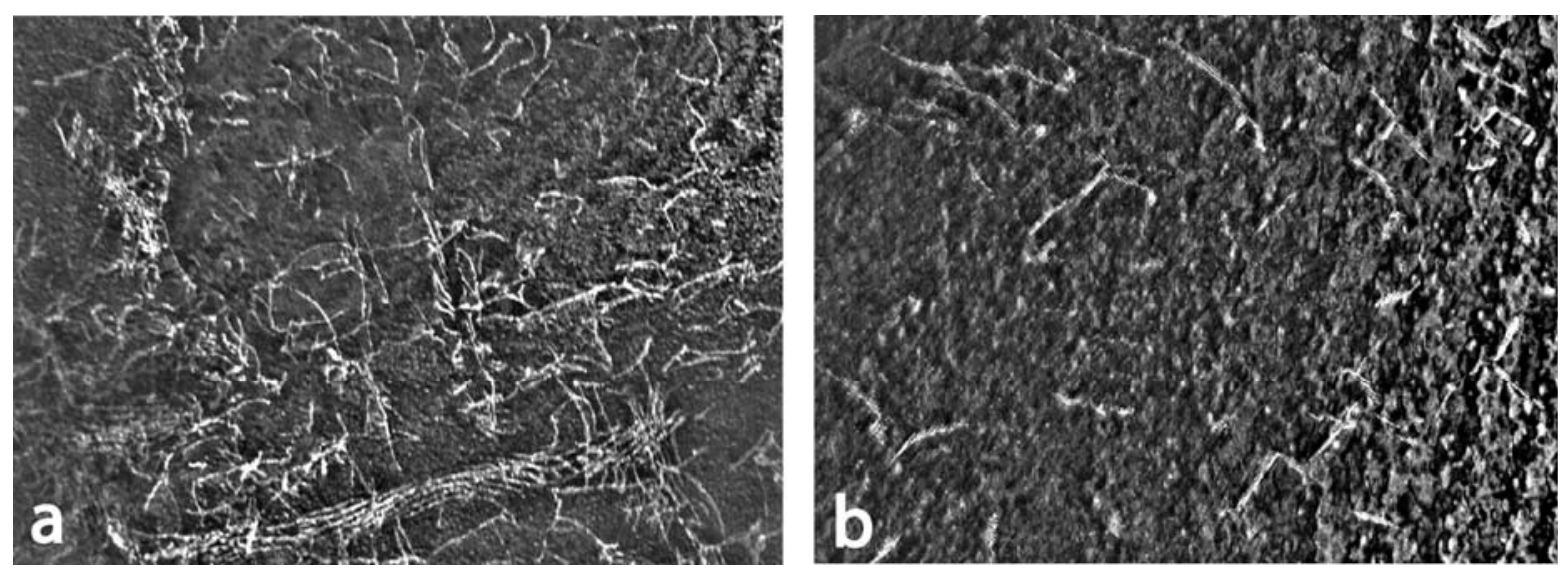

Figure 10. Distribution of dislocations in fusion zones in (a) DA and (b) STA specimens.

\section{Evolution of Microstructure in HAZ Region}

Detailed TEM investigation revealed that $\gamma^{\prime \prime}$ particles have completely dissolved up to a distance of about $300 \mu \mathrm{m}$ from the weld interface and the particle size gradually reached the base metal value at about 600 to $650 \mu \mathrm{m}$ from the fusion zone interface. This observation is indicative of 

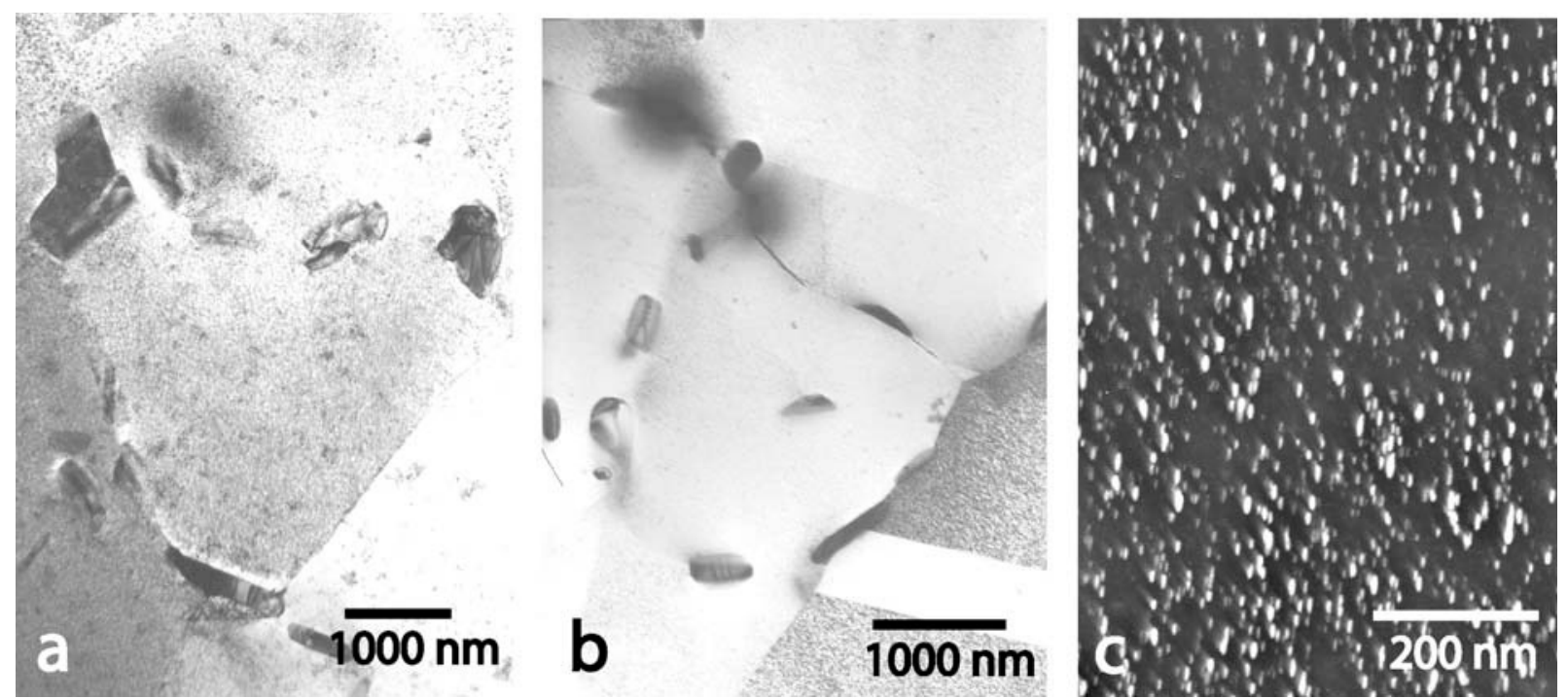

Figure 11. Typical microstructure of HAZ in (a) DA and (b) STA speciemens. (c) Precipitation of $\gamma^{\prime \prime}$ particles in HAZ after post weld heat treatment.

the fact that the temperature in region B has risen above the dissolution temperature of $\gamma^{\prime \prime}$ particles in the alloy which is above $900^{\circ} \mathrm{C}$ but below $1000^{\circ} \mathrm{C}$ above which rapid grain coarsening has been observed to occur[1,13]. The time spent at this temperature is just sufficient or more for its complete dissolution. Since $\gamma^{\prime \prime}$ precipitation is not noticed in region $\mathrm{B}$, the total time taken to cool to a temperature where kinetics do not favour $\gamma^{\prime \prime}$ formation appears to be less than the incubation time for $\gamma^{\prime \prime}$ nucleation reported in the TTT diagram for this alloy[1,2]. Another interesting observation is that in the entire HAZ region, the $\gamma^{\prime \prime}$ particle size is either less than (region $\mathrm{C}$ ) or equal to (region $\mathrm{D}$ and beyond) the average size for the base material though excursion to higher temperature has occurred here. Such decrease in $\gamma^{\prime \prime}$ particle size would occur only if the temperature in region $\mathrm{C}$ has gone above its solvus temperature very quickly and the period of excursion above the solvus temperature is not sufficient for its complete dissolution. Any rise in temperature to a value lower than the $\gamma^{\prime \prime}$ solvus temperature would only result in $\gamma^{\prime \prime}$ particle coarsening. No appreciable particle growth is expected during the cooling period since the $\gamma^{\prime \prime}$ precipitation is very sluggish and is consistent with the present experimental observation. At distances far away from the interface (the region D and E ), the experimental observation of $\gamma^{\prime \prime}$ particle size equal to that of base material value indicate that the appreciable temperature might not have happened to cause any significant change in their size or volume fraction.

Table II. $\gamma^{\prime \prime}$ particle size as a function of different distances from fusion zone interface in as welded, DA and STA specimens.

\begin{tabular}{|c|c|c|}
\hline Sample designation & Area identification & $\gamma^{\prime \prime}$ particle size $(\mathrm{nm})$ \\
\hline & A & - \\
B & - \\
As welded & C & 9.4 \\
& D & 10.8 \\
& E & 11.4 \\
\hline DA & F & 12.6 \\
& G & 15.6 \\
\hline STA & H & 11.3 \\
& I & 11.6 \\
\hline
\end{tabular}


Another important feature of this study is the observation of high density of dislocations in the fusion zone and the heat affected zone close to the fusion zone interface and its gradual reduction as one goes further away from the fusion zone interface. These dislocations appeared to be generated to accommodate stresses generated during welding in these regions. The total stress generated in region $\mathbf{B}$ is the sum of stresses due to thermal expansion as a result of temperature rise and also due to dissolution of $\gamma^{\prime \prime}$ particles at temperatures above $\gamma^{\prime \prime}$ solvus temperature which has been reported to result in increase in dimension of the material. When this stress is greater than the yield strength of the material, dislocations are generated to accommodate it. The yield stress of solution treated Alloy 718 at room temperature is about $350 \mathrm{MPa}$ [14]. The hardness value obtained at this temperature corresponds to hardness value expected for fully annealed Alloy 718 material. From the above discussion, one could conclude that these dislocations might have been generated in region $\mathrm{B}$ to accommodate partially the thermal stresses. In the region $\mathrm{C}$, the hardness has reached a value close to that of peak aged condition. Since shearing of $\gamma^{\prime \prime}$ particles by dislocations and stacking faults could be noticed, the stresses at this point should have reached above the yield strength of the material for this particle size which has been estimated to be about $\sim 750 \mathrm{MPa}$ [14]. In fact, Roberts et al [16] have reported that in the case of electron beam welded Waspalloy, residual stresses reach a value close to the yield strength in aged condition at some distance from the fusion zone HAZ interface. Such stresses can generate dislocations which would plastically deform the material in precipitation hardened systems resulting in its confinement to slip bands [17] which are seen as deformation bands in the optical scale. At distances farther away from the weld interface (region E) the maximum temperature rise seen might not be sufficient to bring about any microstructural changes nor the thermal stresses generated high enough to cause plastic deformation of the material.

\section{Conclusions}

No micro- cracks or fissures are observed in as welded or post weld heat treated alloy 718 samples and is attributed to the duplex microstructure consisting of very fine and large grains. Microhardness values dropped to that of solution treated sample in region B in HAZ in as welded sample and is attributed to the dissolution of $\gamma^{\prime \prime}$ particles. Post weld heat treatments (DA and STA) result in the same microhardness values in the fusion and HAZ regions due to uniform precipitation of $\gamma^{\prime \prime}$ particles. Deformation bands in region $\mathrm{C}$ in as welded sample have formed due to shearing of $\gamma^{\prime \prime}$ particles by dislocations and stacking faults which are generated to accommodate high residual stresses.

\section{Acknowledgements}

The authors are thankful to Dr. S. Banerjee, Director, BARC and Shri B. P. Sharma, Associate Director, Materials group, BARC for constant encouragement. The authors are also grateful to Dr. B. K. Subhas of GTRE for providing the electron beam welded Alloy 718 samples. This research was financed by GTRE, Bangalore, India under contract No: MMKV/LPC/7083/96-97.

\section{References}

1. E.E. Brown and D. R. Muzyka, “Nickel- Iron Alloys”, The Superalloys II, ed., C. T. Sims, N. S. Stoloff and W. C. Hagel (New York, NY: John Wiley, 1987), 165-187.

2. H. L. Eiselstein, "Advances in the Technology of Stainless Steels and Related Alloys", STP369, (ASTM, Philadelphia, PA, 1965), 62-67. 
3. M. H. McCay et al., "Laser Welding Techniques for Alloy 718", Superalloys 718, 625and Various Derivatives, Ed., E. A. Loria, (Warrendale, PA: TMS, 1991), 719-734.

4. B. Radhakrishnan and R. G. Thomson, The Effect of Heat Affected Zone(HAZ) Liquation Kinetics on the Hot Cracking Susceptibility of Alloy 718”, Metall. Trans., 23A,(1993), 14091422.

5. R. Vincent, "Precipitation around Welds in the Nickel Base Superalloy Inconel 718", Acta Metall., (1985), 1205-1216.

6. M. C. Chaturvedi et al., "The Effect of Boron Segregation on Heat Affected Zone Microfissuring in EB Welded Inconel 718", Superalloys 718, 625, 706 and Various Derivatives, Ed., E. A. Loria, (Warrendale, PA: TMS, 1997), 743-751.

7. D. F. Paoulonis, J. M. Oblak and D. S. Duvall, "Precipitation in Nickel Base Alloy 718", Trans. ASM., 62(1969), 611-622.

8. M. Sundararaman, P. Mukhopadhyay and S. Banerjee, "Some Aspects of the Precipitation of Metastable Intermetallic Phases in Inconel 718”, Metall. Trans., 23A (1992), 2015-2028.

9. M. Sundararaman, P. Mukhopadhyay and S. Banerjee, "Precipitation and Room Temperature Deformation Behaviour of Inconel 718", Superalloys 718, 625, 706 and Various Derivatives, Ed., E. A. Loria, ( Warrendale, PA: TMS, 1994), 419-440.

10. M. Sundararaman, $\mathrm{P}$. Mukhopadhyay and $\mathrm{S}$. Banerjee, "Precipitation of the $\mathrm{Ni}_{3} \mathrm{Nb}$ Phase in Two Nickel Base Superalloys", Metall. Trans., 19A (1988), 453-465.

11. M. Sundararaman and P. Mukhopadhyay, "Carbide Precipitation in Inconel 718", High Temperature Materials and Processes, 11 (1993), 351-368.

12. Ya-Fang Han, P.Deb and M. C. Chaturvedi, "Coarsening Behaviour of $\gamma$ " and $\gamma^{\prime}$ Particles in Inconel 718 Alloy”, J. Metal Science, 16 (1982), 555-561.

13. T. Banik, S.O. MANcuso and G. E. Maurer, "An Evaluation of the Forgeability of Delta Processed Udimet Alloy 718DP”, ", Superalloys 718, 625, 706 and Various Derivatives, Ed., E. A. Loria, ( Warrendale, PA: TMS, 1994), 273-280.

14. M. Sundararaman, P. Mukhopadhyay and S. Banerjee, "Deformation Behaviour of $\gamma$ " Strengthened Inconel 718", Acta Metall., 36 (1988), 847-864.

15. W.A. Baselack III, S. L. West and T. J. Kelly, "Weld Cracking in Ta- Modified Cast Inconel 718”, Scripta Metall., 22 (1988), 729-734.

16. S.M. Roberts, O. Hunziker, D. Dye, H. J. Stone and R. C. Reed, "Nickel Base Superalloy Welding Models for Residual Stress, Distortion and Weldability", Recent Advances in Welding Simulation, I MechE Seminar Publication, (2000-13), 33-43.

17. M. Sundararaman et al., "Transmission Electron Microscopic Investigations of $\gamma$ ' Free Bands in Nimonic PE16 under LCF Loading at Room Temperature", Acta Metall. Mater., 38 (1990), 1813-1822. 